Published in final edited form as:

Biochemistry. 2018 June 05; 57(22): 3167-3175. doi:10.1021/acs.biochem.7b01213.

\title{
Mechanism and Structure of $\gamma$-Resorcylate Decarboxylase
}

\author{
Xiang Sheng ${ }^{\phi}$, Yury Patskovsky ${ }^{\Psi}$, Anna Vladimirova $^{\Omega}$, Jeffrey B. Bonanno ${ }^{\Psi}$, Steven C. \\ Almo ${ }^{\Psi,{ }^{*}}$, Fahmi Himo ${ }^{\phi,}{ }^{*}$, and Frank M. Raushel ${ }^{\Omega,{ }^{*}}$ \\ \$Department of Organic Chemistry, Arrhenius Laboratory, Stockholm University, SE-106 91 \\ Stockholm, Sweden \\ ${ }^{\Omega}$ Department of Chemistry, Texas A\&M University, College Station, Texas, 77842, United States \\ ${ }^{\Psi}$ Albert Einstein College of Medicine, 1300 Morris Park Avenue, Bronx, New York 10461, United \\ States
}

\section{Abstract}

$\gamma$-Resorcylate decarboxylase ( $\gamma$-RSD) has evolved to catalyze the reversible decarboxylation of 2,6-dihydroxybenzoate to resorcinol in a nonoxidative fashion. This enzyme is of significant interest because of its potential for the production of $\gamma$-resorcylate and other benzoic acid derivatives under environmentally sustainable conditions. Kinetic constants for the decarboxylation of 2,6-dihydroxybenzoate catalyzed by $\gamma$-RSD from Polaromonas sp. JS666 are reported and the enzyme is shown to be active with 2,3-dihydroxybenzoate, 2,4,6trihydroxybenzoate and 2,6-dihydroxy-4 methylbenzoate. The three-dimensional structure of $\gamma$ RSD with the inhibitor 2-nitroresorcinol (2-NR) bound in the active site is reported. 2-NR is directly ligated to a $\mathrm{Mn}^{2+}$ bound in the active site and the nitro-substituent of the inhibitor is tilted significantly from the plane of the phenyl ring. The inhibitor exhibits a different binding mode compared to the substrate bound in the previously determined structure of $\gamma$-RSD from Rhizobium sp. MTP-10005. On the basis of the crystal structure of the enzyme from Polaromonas sp. JS666, complementary density functional calculations were performed to investigate the reaction mechanism. In the proposed reaction mechanism, $\gamma$-RSD binds 2,6-dihydroxybenzoate by direct coordination of the active site manganese ion to the carboxylate anion of the substrate and one of the adjacent phenolic oxygens. The enzyme subsequently catalyzes the transfer of a proton to $\mathrm{C} 1$ of $\gamma$-resorcylate prior to the actual decarboxylation step. The reaction mechanism proposed previously, based on the structure of $\gamma$-RSD from Rhizobium sp. JS666, is shown to be associated with high energies and thus less likely to be correct.

\section{TOC image}

\footnotetext{
*Corresponding Authors: S. C. A.: steve.almo@einstein.yu.edu; F. H.: fahmi.himo@su.se; F. M. R.: raushel@tamu.edu. Supporting Information

The Supporting Information is available free of charge on the ACS Publications website at DOI:

Additional results concerning the alternative mechanisms and Cartesian coordinates of optimized structures.

Notes

The authors declare no competing financial interest.
} 


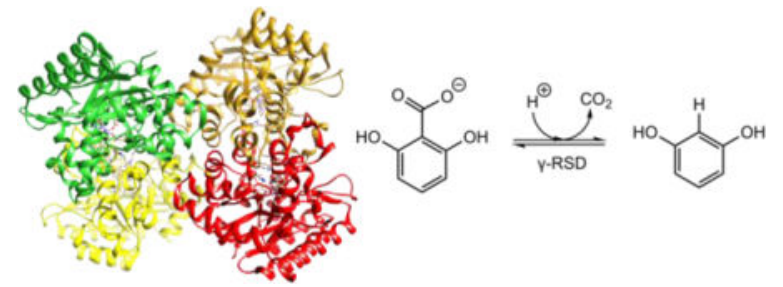

\section{Introduction}

$\gamma$-Resorcylate decarboxylase ( $\gamma$-RSD), also called 2,6-dihydroxybenzoate decarboxylase (2,6-DHBD), catalyzes the nonoxidative reversible decarboxylation of $\gamma$-resorcylate $(\gamma$-RS; 2,6-dihydroxybenzoate) to resorcinol (1,3-dihydroxybenzene) and $\mathrm{CO}_{2}$ as shown in Scheme 1a $(1,2)$. The resorcinol product of the decarboxylation activity is an important intermediate in the fields of organic, pharmaceutical, agricultural and polymer chemistries, and $\gamma$-RSD can be used as a biocatalyst to produce this valuable compound (3). Recently, the carboxylation activity of $\gamma$-RSD has attracted increasing attention as a potential biological alternative to the Kolbe-Schmitt process (4), which requires harsh conditions in terms of pressure and temperature, for the production of $\gamma$-resorcylate and other benzoic acid derivatives (5-10).

$\gamma$-RSD has been characterized from several bacterial species, including Rhizobium $s p$. MTP-10005 (11), Rhizobium radiobacter WU-0108 (12), Agrobacterium tumefaciens IAM12048 (13), Pandoraea sp. 12B-2 (14) and Rhodococcus jostii RHA1 (15). In the $\gamma$ resorcylate catabolic pathway identified in Rhizobium sp. MTP-10005, the gene for $\gamma$-RSD is downstream from genes encoding a flavin reductase and a resorcinol hydroxylase and is upstream from genes encoding a maleylacetate reductase and hydroxyquinol 1,2dioxygenase (16). The enzyme from Rhizobium sp. MTP-10005 has been shown to be a reversible decarboxylase with reported kinetic parameters for $k_{\mathrm{cat}}, K_{\mathrm{m}}$ and $k_{\mathrm{cat}} / K_{\mathrm{m}}$ of $0.95 \mathrm{~s}$ ${ }^{-1}, 71 \mu \mathrm{M}$ and $1.3 \times 10^{4} \mathrm{M}^{-1} \mathrm{~s}^{-1}$, respectively, for the decarboxylation of $\gamma$-resorcylate (11). Crystal structures were later determined for the apo-enzyme and in the presence of substrate or inhibitor, demonstrating that the enzyme exists as a homotetramer, of which each subunit consists of a $(\beta / a)_{8}$-barrel, three linkers and a C-terminal tail (17).

The enzyme 5-carboxyvanillate decarboxylase (LigW) from Novosphingobium aromaticivorans DSM 12444, catalyzing the formation of vanillate via the nonoxidative decarboxylation of 5-carboxyvanillate (Scheme 1b), is the closest structurally characterized homologue of $\gamma$-RSD from Rhizobium sp. JS666 with a 33\% sequence identity. Both enzymes are members of $\operatorname{cog} 2159$ of the amidohydrolase superfamily (AHS), and these enzymes require a single divalent metal for catalysis (18). The structure of $\gamma$-RSD from Rhizobium sp. JS666 has previously been determined in complex with substrate (PDB id: 2DVU). A zinc ion was observed in the active site and was coordinated by two histidines, one glutamate, one aspartate and one oxygen atom of the substrate carboxylate group (17). In contrast, a manganese ion has been identified in LigW, and the substrate is suggested to bind such that both the hydroxyl group and the carboxylate group are coordinated to the metal ion (19). Due to the high similarity in the reactions catalyzed by $\gamma$-RSD and LigW 
(Scheme 1), it is of interest to compare their structures and catalytic reaction mechanisms. Furthermore, since both enzymes belong to the amidohydrolase superfamily, the members of which predominantly catalyze the hydrolysis of ester and amide bonds, it is of substantial importance to understand how these enzymes have evolved to catalyze the reversible decarboxylation of benzoic acid derivatives (18).

In the present study, we report the catalytic activity, substrate specificity and crystal structure of $\gamma$-RSD from Polaromonas sp. JS666 (locus tag: Bpro_2061) in complex with the substrate analog inhibitor, 2-nitroresorcinol. On the basis of the crystal structure reported here, complementary theoretical calculations were performed with density functional theory to investigate the reaction mechanism. The calculations show that $\gamma$-RSD follows a very similar mechanism as LigW. The mechanism proposed previously on the basis of the $\mathrm{Zn}$ structure of the enzyme from Rhizobium sp. MTP-10005 is shown to be associated with high energies and thus less likely to be correct.

\section{Materials and Methods}

\section{Materials}

All chemicals, buffers, and purification reagents were purchased from Sigma-Aldrich unless otherwise specified. Pfu Turbo DNA polymerase and the E. coli strains BL21 (DE3) and XL1-blue cells were obtained from Stratagene. The restriction enzyme DpnI was purchased from New England BioLabs and oligonucleotides were obtained from Integrated Data Technology through the Gene Technology Laboratory at Texas A\&M University. Kanamycin, isopropyl $\beta$-D-thiogalactopyranoside (IPTG), and LB broth were acquired from Research Products International Corp. Protamine sulfate, Wizard Plus SV Miniprep DNA purification system, and Vivaspin centrifugal concentrator (10 $000 \mathrm{MWCO})$ were obtained from MP Biomedicals LLC., Promega, and Fisher Scientific, respectively. Chromatographic gel filtration columns were purchased from GE Healthcare. 2-Nitroresorcinol was purchased from Sigma Aldrich.

\section{Expression and Purification of $\gamma$-Resorcylate Decarboxylase ( $\gamma$-RSD) from Polaromonas sp. JS666}

The gene for $\gamma$-RSD (Bpro_2061; gi: 91787937) from Polaromonas sp. JS666 was chemically synthesized. The clone contained the codon-optimized gene for $\gamma$-RSD with an $N$-terminal Met-Val extension and a $C$-terminal Ala-Glu-Asn-Leu-Tyr-Phe-Gln-Ser-His 6 extension. The His 6 -tagged protein was used for crystallographic studies while the $C$ terminal His-tag was removed for preparation of the enzyme used to measure the kinetic parameters via standard site-directed mutagenesis protocols using the primers $5^{\prime}$ GAGAACCTCTACTTCTAATAGCACCATCATCACCACCAT-3' (forward) and 5' ATGGTGGTGATGATGGTGCTATTAGAAGTAGAGGTTCTC-3' (reverse). The recombinant plasmid was transformed by electroporation into BL21 (DE3) cells, which were plated on agar containing $50 \mu \mathrm{g} / \mathrm{mL}$ kanamycin. Six colonies were inoculated into $7 \mathrm{~mL}$ of LB broth containing $7 \mu \mathrm{g} / \mathrm{mL}$ kanamycin and grown overnight at $37{ }^{\circ} \mathrm{C}$. The starting cultures were used to inoculate a total of $6.0 \mathrm{~L}$ of LB broth containing $50 \mu \mathrm{g} / \mathrm{mL}$ kanamycin and left to incubate at $37^{\circ} \mathrm{C}$ by shaking. Isopropyl $\beta$-thiogalactoside (IPTG) was added to a 
final concentration of $0.5 \mathrm{mM}$ to each of the flasks once the absorbance reached a range between 0.4-0.6 OD. Upon induction, 2.0 L of cells were supplemented with $1.0 \mathrm{mM}$ $\mathrm{MnCl}_{2}$. Expression of the protein was achieved by shaking at $22^{\circ} \mathrm{C}$ overnight. The cells were collected by centrifugation $(8,000 \mathrm{rpm}$ for $10 \mathrm{~min})$ and stored at $-80^{\circ} \mathrm{C}$.

His-tagged protein for crystallographic studies was purified to homogeneity using general methods, which have been described (20). Purification of the enzyme used to measure the kinetic parameters followed the methods described below. The frozen cells were thawed at room temperature and resuspended in $20 \mathrm{mM}$ HEPES ( $\mathrm{pH} 7.5$ ) containing $20 \mathrm{mg}$ phenylmethanesulfonyl fluoride (PMSF) for every $5 \mathrm{~g}$ of cells. Lysis was achieved by sonication, followed by centrifugation at $8,000 \mathrm{rpm}$ for $10 \mathrm{~min}$, and addition of $0.1 \mathrm{~g}$ of protamine sulfate dissolved in $10 \mathrm{~mL}$ of $20 \mathrm{mM}$ HEPES (pH 7.5) over a period of $45 \mathrm{~min}$. The solution was centrifuged at $8,000 \mathrm{rpm}$ for $10 \mathrm{~min}$ and ammonium sulfate was added to the supernatant solution to achieve $45 \%$ saturation. After stirring for $45 \mathrm{~min}$, the suspension was centrifuged at $8,000 \mathrm{rpm}$ for $10 \mathrm{~min}$. The pellet was re-suspended in $10 \mathrm{~mL}$ of $20 \mathrm{mM}$ HEPES, pH 7.5, and loaded onto a 26/60 Superdex 200 gel-filtration column. The protein was eluted using $20 \mathrm{mM}$ HEPES, $\mathrm{pH} 7.5$, and further loaded on a Resource-Q (GE Healthcare) anion-exchange column $(6.0 \mathrm{~mL}) \cdot \gamma$-RSD was eluted using a linear gradient of $1.0 \mathrm{M} \mathrm{NaCl}$ in $20 \mathrm{mM}$ HEPES, $\mathrm{pH}$ 7.5. The purified protein was concentrated and subsequently stored at $-80{ }^{\circ} \mathrm{C}$.

\section{Determination of Kinetic Parameters}

The decarboxylation of $\gamma$-resorcylate by $\gamma$-RSD was monitored by following the decrease in absorbance at $305 \mathrm{~nm}$ using a differential molar extinction coefficient $\left(\Delta \varepsilon_{305}\right)$ of $3,208 \mathrm{M}^{-1}$ $\mathrm{cm}^{-1}$. The decarboxylation of 2,3-dihydroxybenzoate, 2,4,6-trihydroxybenzoate, and 2,6dihydroxy-4-methylbenzoate was monitored by following the decrease in absorbance at 306, 256 , and $304 \mathrm{~nm}$ using differential extinction coefficients $\left(\Delta \varepsilon_{306}\right)$ of $3680 \mathrm{M}^{-1} \mathrm{~cm}^{-1}$, $\left(\Delta \varepsilon_{256}\right)$ of $5953 \mathrm{M}^{-1} \mathrm{~cm}^{-1}$, and $\left(\Delta \varepsilon_{304}\right)$ of $2977 \mathrm{M}^{-1} \mathrm{~cm}^{-1}$, respectively. All assays were conducted using a 96-well SpectraMax Plus384 UV-vis spectrophotometer and the steadystate kinetic parameters were obtained using SoftMax Pro 5.0. Standard assay conditions for the decarboxylation of 2,6-dihydroxybenzoate, 2,3-dihydroxybenzoate, 2,4,6trihydroxybenzoate, and 2,6-dihydroxy-4-methylbenzoate contained $50 \mathrm{mM}$ HEPES ( $\mathrm{pH}$ $7.0)$, substrate $\left(0-500 \mu \mathrm{M}\right.$, and $0.1 \mu \mathrm{M} \gamma$-RSD in a final volume of $250 \mu \mathrm{L}$ at $30^{\circ} \mathrm{C}$. All of the kinetic constants were obtained using eqn. 1 , where $v$ is the initial velocity, $\mathrm{E}_{\mathrm{t}}$ is the total enzyme concentration, [A] is the substrate concentration, $k_{\text {cat }}$ is the turnover number, and $K_{\mathrm{m}}$ is the Michaelis constant.

$$
v / \mathrm{E}_{\mathrm{t}}=k_{\mathrm{cat}}[\mathrm{A}] /\left(K_{\mathrm{m}}+[\mathrm{A}]\right)
$$

\section{Inhibition Studies}

2-Nitroresorcinol (2-NR) was utilized as an inhibitor for the reaction catalyzed by $\gamma$-RSD. The inhibition experiments for 2-NR contained $60 \mu \mathrm{M} \gamma$-resorcylate, $50 \mathrm{mM}$ HEPES, $\mathrm{pH}$ 7.0, and $1.0 \mu \mathrm{M} \gamma$-RSD in a total volume of $250 \mu \mathrm{L}$ at $30^{\circ} \mathrm{C}$. The apparent inhibition 
constant $\left(K_{\mathrm{i}}^{\mathrm{app}}\right)$ for 2-NR was obtained from a fit of the data to eqn. 2 , where [I] is the inhibitor concentration, $v_{\mathrm{O}}$ is the velocity in absence of inhibitor, and $v_{\mathrm{i}}$ is the velocity in presence of inhibitor. The $K_{\mathrm{d}}$ value was obtained from eqn. 3 , where [S] is the substrate concentration used in the inhibition experiment and $K_{\mathrm{m}}$ is the Michaelis constant for the substrate.

$$
\begin{gathered}
v_{\mathrm{i}} / v_{\mathrm{o}}=K_{\mathrm{i}}^{\mathrm{app}} /\left([\mathrm{I}]+K_{\mathrm{i}}^{\mathrm{app}}\right) \\
K_{\mathrm{i}}^{\text {app }}=K_{\mathrm{d}}\left(1+[\mathrm{S}] / K_{\mathrm{m}}\right)
\end{gathered}
$$

\section{Crystallization, X-ray Data Collection, and Structure Determination}

$\gamma$-RSD was crystallized by the sitting-drop vapor diffusion method. Concentrated ( $\sim 15$ $\mathrm{mg} / \mathrm{mL})$ protein solutions were mixed with an equal volume of precipitant $(0.5 \mu \mathrm{L})$ and equilibrated at room temperature against the same precipitant solution in clear tape-sealed 96-well INTELLI-plates (Art Robbins Instruments, Sunnyvale, CA). Crystallization screens were performed with a PHENIX liquid handling robot (Art Robbins Instruments). The protein crystallized from the mother liquor composed of $0.10 \mathrm{M}$ sodium acetate, $\mathrm{pH} 4.6,1.0$ $\mathrm{M}$ dibasic ammonium citrate, and $5.0 \mathrm{mM} \mathrm{MnCl}_{2}$. Crystals were soaked in this solution supplemented with $10 \mathrm{mM}$ 2-nitroresorcinol overnight, followed by flashed-cooling and storage in liquid nitrogen.

X-ray diffraction data were collected at $100 \mathrm{~K}$ on the X29A beamline (National Synchrotron Light Source, Brookhaven National Laboratory, Upton, NY) at a wavelength of $1.075 \AA$. The diffraction data were processed and scaled with HKL3000 (21). The crystal structure was determined by molecular replacement using the coordinates of Protein Data Bank (PDB) entry 3S4T as a starting model and PHASER software as implemented in CCP4 (22). The initial model was built and refined using the automated ARP/WARP protocol (23). The model was further refined using REFMAC5 (24) and manually adjusted using COOT visualization and refinement software (25). The structure was deposited to the PDB as entry 4QRO. All figures were produced using PYMOL (26). The data collection and refinement statistics for the crystal structure are listed in Table 1.

\section{Computational Details}

All the calculations in the present study were preformed employing the Gaussian 09 program (27) with the B3LYP-D3(BJ) hybrid density functional method (28-31). Geometry optimizations were conducted with the 6-31G(d,p) basis set for $\mathrm{C}, \mathrm{N}, \mathrm{O}$ and $\mathrm{H}$ and LANL2DZ pseudopotential for Mn and Zn (32). At the same level, frequency calculations were preformed to obtain zero-point energies (ZPE). To consider the effects of the rest of the enzyme that is not included in the model, single-point energy calculations were carried out at the same level of theory as the geometry optimization using SMD solvation model with the value of dielectric constant $\varepsilon=4$ (33). To obtain more accurate energies, single-point 
calculations on the optimized structures were performed with LANL2DZ for Mn and Zn and the larger basis set $6-311+G(2 d, 2 p)$ for the other atoms. The ZPE and solvation effects are then added to the large basis set energies (that include dispersion) and the final values are presented in this paper. Following previous studies on other decarboxylation reactions, the entropy gain from the release of $\mathrm{CO}_{2}$ is estimated to be equal to the translational entropy for the free molecule (34-36). The value is calculated to be $11.1 \mathrm{kcal} / \mathrm{mol}$ at room temperature and this value is added to the energy of the corresponding step.

\section{Active Site Model}

To investigate the detailed mechanism of the decarboxylation reaction catalyzed by $\gamma$-RSD, quantum chemical calculations employing the cluster approach (37-41) were performed on the basis of the crystal structure in complex with 2-nitroresorcinol reported here. A large active site model is designed by modifying the inhibitor to the natural substrate, 2,6dihydroxybenzoate. The model consists of the metal cation along with its ligands (Glu8, His10, His164, Asp287 and 2,6-dihydroxybenzoate), six crystallographic water molecules, residues that potentially form hydrogen bonds with the substrate directly or via water molecules (Ser20, Asn128, His218, Glu221, Arg229, Asn234 and Glu291), residues that are $\pi$-stacked to the aromatic ring of the substrate (Phe23, Phe189 and Phe290), as well as other residues that also contribute to the active site (Leu32, Leu36, Ala61, Gly184, Pro185, Thr186 and Ser262). All amino acids were truncated at the a-carbons, and hydrogen atoms were added manually. To preserve the overall structure of the active site during geometry optimizations, the truncated a-carbons and also a number of connected hydrogen atoms were kept fixed at their crystallographic positions, as indicated in the figures. The Mncoordinated hydroxyl group of the substrate is assumed to lose its proton upon binding to the metal, and the potential general acid group Asp287 is modeled as its neutral state. The overall model consists of 317 atoms and is neutral in charge.

\section{Results and Discussion}

\section{Purification and Properties of $\gamma$-RSD from Polaromonas sp. JS666}

$\gamma$-RSD was purified to homogeneity using a simple protocol that involved ammonium sulfate fractionation, gel filtration, and ion exchange chromatography. The purified enzyme was shown to catalyze the decarboxylation of $\boldsymbol{\gamma}$-resorcylate to resorcinol, 2,3dihydroxybenzoate to catechol, 2,4,6-trihydroxybenzoate to benzene-1,3,5-triol, and 2,6dihydroxy-4-methylbenzoate to 5-methylbenzene-1,3-diol. The catalytic constants for the decarboxylation reactions are presented in Table 2 from a fit of the data to eqn. 1 . The values of $k_{\text {cat }}$ and $k_{\text {cat }} / K_{\mathrm{m}}$ for the decarboxylation of $\gamma$-resorcylate are $0.44 \pm 0.01 \mathrm{~s}^{-1}$ and (1.3 $\pm 0.1) \times 10^{4} \mathrm{M}^{-1} \mathrm{~s}^{-1}$, respectively. The kinetic constants for the other compounds found to be substrates for this enzyme are quite similar, demonstrating that the enzyme is quite tolerant of the addition of other hydroxyl groups at $\mathrm{C} 3, \mathrm{C} 4$, and $\mathrm{C} 6$.

2-Nitroresorcinol (2-NR) was identified as an inhibitor of the reaction catalyzed by $\gamma$-RSD. An apparent inhibition constant $\left(K_{\mathrm{i}}^{\text {app }}\right)$ of $96 \pm 8 \mu \mathrm{M}$ was obtained at a fixed substrate concentration of $60 \mu \mathrm{M}$ (Figure 1) by a fit of the data to eqn. 2. The dissociation constant for 
the binding of 2-NR was determined to be $40 \pm 4 \mu \mathrm{M}$ after correcting for the concentration of the substrate used in the experiments with eqn. 3 .

\section{Crystal Structure of $\gamma$-RSD}

The crystal structure of $\gamma$-RSD from Polaromonas sp. JS666 complexed with 2nitroresorcinol and $\mathrm{Mn}^{2+}$ was determined to $1.65 \AA$ resolution (PDB entry 4QRO). The quaternary structure of $\gamma$-RSD is a homotetramer, but the minimal catalytic state is a homodimer (Figure 2). An essential arginine residue that is conserved in all of the decarboxylases from $\operatorname{cog} 2159$ extends from the adjacent subunit into the active site and presumably stabilizes the carboxylate substituent of the substrate.

Each of the four subunits consists of a distorted $(\beta / \alpha)_{8}$-barrel protein fold with the active site and $\mathrm{Mn}^{2+}$ embedded at the $\mathrm{C}$-terminal end of the barrel. A helical insertion domain is observed (amino acids 12-39) with the side chain of Phe23 in a "herring-bone like" interaction with the phenyl ring of the inhibitor at a van der Waals distance of $3.8 \AA$. The inhibitor is further stabilized in the active site through $\pi-\pi$ stacking with Phe290 at a distance of $3.5 \AA$. His 218 and Glu221 form a hydrogen-bonded triad with Asp287 from $\beta$ strand 8 as shown in Figure 3a. As stated above, Arg229 from the adjacent monomer is within $3.2 \AA$ of one of the oxygen atoms of the $\mathrm{C} 1$ nitro group; Asn234 from the same subunit as Arg229 hydrogen bonds to the hydroxyl group at C6 (Figure 3a).

The single divalent cation is bound in the active site in an octahedral geometry (Figure 3a). The residues important for binding $\mathrm{Mn}^{2+}$ include a glutamate and a histidine from the ExH motif found at the end of $\beta$-strand 1 (Glu8 and His10), a histidine from $\beta$-strand 5 (His164), and an aspartate from $\beta$-strand 8 (Asp287). The remaining two ligands include the nitrosubstituent of the inhibitor and the adjacent phenolic oxygen. Most notably, the geometry of the inhibitor deviates significantly from planarity. In particular, the nitro group at $\mathrm{C} 1$ is tilted from the plane of the phenyl ring plane with a torsion angle of $51^{\circ}$. Interestingly, both the $\mathrm{Mn}^{2+}$ coordination geometry and the mode of inhibitor binding are very similar to those observed in the very high resolution X-ray structure of LigW in complex with 2nitrovanillate (Figure 3b) (19).

The expected high degree of similarity between $\gamma$-RSD from Polaromonas sp. JS666 and Rhizobium sp. MTP-10005 was borne out by three dimensional structural alignments, which revealed an agreement of $77 \%$ sequence identity and $0.36 \AA$ RMSD over 317 aligned $\mathrm{Ca}$ atom (PDB entry 4QRO compared to 2DVX). Likwise, $\gamma$-RSD from Polaromonas aligned fairly well with LigW from Sphingomonas paucimobilis, despite modest sequence identity (4QRO versus $4 \mathrm{INF}, 37 \%$ sequence identity, 1.38 A RMDS over 282 aligned $\mathrm{Ca}$ atoms).

\section{Reaction Mechanism}

The optimized structure of the enzyme-substrate complex (called E:S) is shown in Figure 4. The substrate retains a very similar binding mode as the inhibitor in the crystal structure. The carboxylate group forms hydrogen bonds with Asp287, Arg229, Wat1 and also the C6 hydroxyl group, which hydrogen bonds to Asn234. The deprotonated C2 hydroxyl group interacts with Ser20 and Asn128 through three water molecules. It is noteworthy that this binding mode bears a very high similarity to that of LigW, suggesting a structural basis for a 
similar reaction mechanism $(19,36)$. For $\gamma$-RSD the reaction would likely start with the protonation of the $\mathrm{C} 1$ atom of the substrate by Asp287, followed by $\mathrm{C}-\mathrm{C}$ bond cleavage to generate the $\mathrm{CO}_{2}$ and resorcinol products.

Starting from the enzyme-substrate complex $\mathbf{E}: \mathbf{S}$, the protonation of the substrate $\mathrm{C} 1$ carbon by Asp287 first takes place. This step is calculated to be rate-limiting with a barrier of 14.8 $\mathrm{kcal} / \mathrm{mol}$, and the resulting intermediate (Int) is $8.1 \mathrm{kcal} / \mathrm{mol}$ higher in energy than $\mathbf{E}: \mathbf{S}$ (Figure 5). At the optimized transition state for this protonation (TS1), the distances of the breaking $\mathrm{O}-\mathrm{H}$ bond and the forming $\mathrm{C}-\mathrm{H}$ bond are $1.29 \AA$ and $1.40 \AA$, respectively (Figure 6). Next, the $\mathrm{C}-\mathrm{C}$ bond between the carboxylate group and the $\mathrm{C} 1$ atom breaks to form the products. Interestingly, this decarboxylation process is easy with a calculated barrier of only $3.3 \mathrm{kcal} / \mathrm{mol}$ relative to Int, that is $11.4 \mathrm{kcal} / \mathrm{mol}$ higher than $\mathbf{E}: \mathbf{S}$. At the corresponding transition state (TS2), the length of the breaking C-C bond is $2.17 \AA$ (Figure 6). The enzyme-product complex (E:P) is $3.3 \mathrm{kcal} / \mathrm{mol}$ higher than $\mathbf{E}: \mathbf{S}$ (Figure 5), including the contribution of the entropy gain from the release of $\mathrm{CO}_{2}$ as discussed in the Computational Details section. In the E:P structure, the $\mathrm{Mn}^{2+}$ cation becomes five-coordinated.

Very similar coordination was observed in the X-ray structure of LigW from Sphingomonas paucimobilis complexed with the vanillate product (PDB entry 4L6D) (19). The obtained energy profile here for $\gamma$-RSD is also very similar to that calculated for LigW (36). For both enzymes, the proton transfer step corresponds to a higher barrier than the decarboxylation step. Also, the structures of the intermediates and transition states bear high similarities.

\section{Alternative Mechanisms}

As discussed above, several crystal structures of $\gamma$-RSD from another organism, Rhizobium $s p$. MTP-10005, have been reported previously, one of which is an enzyme-substrate complex (PDB entry 2DVU) (17). This enzyme was found to contain zinc in the active site and the substrate binds to the active site such that one oxygen atom of the carboxylate group, but none of the hydroxyl groups, coordinates to the metal ion (17). On the basis of this structure, Asp287 was suggested to be in the deprotonated state, acting as a general base to abstract a proton from the hydroxyl groups of the substrate to initiate the reaction. Protonation of the $\mathrm{C} 1$ carbon can then take place, followed by a $\mathrm{C}-\mathrm{C}$ bond cleavage to generate the products (17).

It is interesting to compare the binding mode of the substrate in $2 \mathrm{DVU}$ with that in $4 \mathrm{QRO}$ and also the feasibility of the reaction mechanisms using the quantum chemical approach employed here. To this end, we have on the basis of the 2DVU structure constructed an active site model (called E:S-Zn, see Figure 7 for optimized structure) for $\boldsymbol{\gamma}$-RSD from Rhizobium sp. This model consists of the same residues as that in $\mathbf{E}: \mathbf{S}$, but with a $\mathrm{Zn}$ instead of $\mathrm{Mn}$ and a different binding mode for the substrate. In E:S-Zn, both hydroxyl groups of the substrate are in the neutral form, and the Asp287 residue is modeled to be in the deprotonated state since it is suggested to act as a general base for the catalysis (17).

Starting from E:S-Zn, the structures of the intermediates involved in the corresponding pathway were optimized (Figure 8). The first intermediate, formed by the proton transfer from the substrate hydroxyl group to Asp287, is calculated to be $19.2 \mathrm{kcal} / \mathrm{mol}$ higher than 
E:S-Zn. The following intermediate, resulting from the proton transfer to $\mathrm{C} 1$ of the substrate, has an even higher energy, $>23 \mathrm{kcal} / \mathrm{mol}$ relative to $\mathbf{E}: \mathbf{S}-\mathbf{Z n}$, regardless of the identity of the proton source (either Asp287 or His218 via a water shuttle, see Scheme 2). These energies are thus prohibitively high and the barriers leading to these intermediates should be even higher (not calculated). Therefore, this mechanistic scenario should be ruled out, and it can be concluded that the binding mode as reported in 2DVU is not a productive mode for catalysis.

Alternatively, we sought to establish whether or not it is possible that the substrate in the $\mathrm{Zn}$ containing enzyme binds to the metal ion similarly to the Mn-dependent enzyme (4QRO), i.e. in a bidentate binding mode as in Figures 3 and 4. In order to examine this possibility, another active site model was constructed by manually repositioning the substrate in E:S-Zn (see SI for the optimized structure). The new enzyme-substrate complex is, however, calculated to have a much higher energy when compared to E:S-Zn, $14.9 \mathrm{kcal} / \mathrm{mol}$, showing that for the Zn-dependent enzyme the binding mode observed in 2DVU is highly preferred. Combined with the prohibitively high barriers for the reaction pathway starting from $\mathbf{E}: \mathbf{S}-\mathbf{Z n}$ as discussed above, one might therefore speculate that the $\mathrm{Zn}$-bound form is not active for $\gamma$ RSD.

Another alternative is whether for the Mn-dependent enzyme the substrate can bind as that in 2DVU, i.e. only by the carboxylate group. By modifying the binding mode of the substrate in $\mathbf{E}: \mathbf{S}$ to resemble 2DVU, we optimized the geometry and calculated the energy of the of this binding mode (see SI for optimized structure). The calculated energy difference between the new structure and $\mathbf{E}: \mathbf{S}$ is very small, only $0.4 \mathrm{kcal} / \mathrm{mol}$ in favor of the former one. This shows that both binding modes are accessible for the Mn-dependent enzyme. However, similarly to the case with E:S-Zn, the intermediates along the reaction pathway were calculated (see SI) and the corresponding energies turned out to be prohibitively high. These calculations thus show that the 2DVU binding mode is likely to be inactive for the Mn-dependent enzyme.

\section{Conclusions}

The catalytic activity, substrate specificity and crystal structure of $\gamma$-RSD have been reported. The values of $k_{\mathrm{cat}}$ and $k_{\mathrm{cat}} / K_{\mathrm{m}}$ for the decarboxylation of $\gamma$-resorcylate are 0.44 $\pm 0.01 \mathrm{~s}^{-1}$ and $(1.3 \pm 0.1) \times 10^{4} \mathrm{M}^{-1} \mathrm{~s}^{-1}$, respectively. In addition to the natural substrate, $\gamma$ RSD is also shown to facilitate the decarboxylation of 2,3-dihydroxybenzoate, 2,4,6trihydroxybenzoate and 2,6-dihydroxy-4 methylbenzoate. We described the crystal structure of the enzyme from Polaromonas sp. JS666 (locus tag: Bpro_2061) in complex with $\mathrm{Mn}^{2+}$ and the substrate analog inhibitor, 2-nitroresorcinol. The binding mode of the inhibitor is different compared to the substrate in the previously reported structure of the enzyme from Rhizobium sp. in complex with $\mathrm{Zn}^{2+}$, and instead shows high similarity to that seen in LigW complexed with 2-nitrovanillate. Theoretical calculations employing density functional theory show that $\gamma$-RSD follows a very similar mechanism as LigW. The reaction starts with the protonation of the carbon atom of the substrate, which is calculated to be the ratelimiting step of the overall reaction. A C-C bond cleavage then takes place to form the products. Additionally, the mechanism proposed previously on the basis of the $\mathrm{Zn}$-structure, 
involving binding of the substrate to the metal ion only by its carboxylate group, is shown to be associated with high energies both for the $\mathrm{Zn}$ - and Mn-bound enzymes.

\section{Supplementary Material}

Refer to Web version on PubMed Central for supplementary material.

\section{Acknowledgments}

This work was supported in part by the Knut and Alice Wallenberg Foundations (to F.H.), the Robert A. Welch Foundation (A-840 to F.M.R.) and the National Institutes of Health (U54 GM093342 to S.C.A).

\section{References}

1. Kluge C, Tschech A, Fuchs G. Anaerobic metabolism of resorcylic acids ( $m$-dihydroxybenzoic acids) and resorcinol (1,3-benzenediol) in fermenting and in a denitrifying bacterium. Arch Microbiol. 1999; 155:68-74.

2. Iwasaki Y, Kino K, Nishide H, Kirimura K. Regioselective and enzymatic production of $\boldsymbol{\gamma}$-resorcylic acid from resorcinol using recombinant Escherichia coli cells expressing a novel decarboxylase gene. Biotechnol Lett. 2007; 29:819-822. [PubMed: 17415666]

3. Durairaj, RB. Resorcinol: Chemistry, Technology, and Applications. Springer-Verlag; Berlin: 2005.

4. Lindsey AS, Jeskey H. The Kolbe-schmitt reaction. Chem Rev. 1957; 57:583-620.

5. Wuensch C, Gross J, Steinkellner G, Lyskowski A, Gruber K, Glueck SM, Faber K. Regioselective ortho-carboxylation of phenols catalyzed by benzoic acid decarboxylases: a biocatalytic equivalent to the Kolbe-Schmitt reaction. RSC Adv. 2014; 4:9673-9679.

6. Ren J, Yao P, Yu S, Dong W, Chen Q, Feng J, Wu Q, Zhu D. An Unprecedented Effective Enzymatic Carboxylation of Phenols. ACS Catal. 2016; 6:564-567.

7. Pesci L, Glueck SM, Gurikov P, Smirnova I, Faber K, Liese A. Biocatalytic carboxylation of phenol derivatives: kinetics and thermodynamics of the biological Kolbe-Schmitt synthesis. FEBS J. 2015; 282:1334-1345. [PubMed: 25652582]

8. Pesci L, Kara S, Liese A. Evaluation of the Substrate Scope of Benzoic Acid (De) carboxylases According to Chemical and Biochemical Parameters. ChemBioChem. 2016; 17:1845-1850. [PubMed: 27505856]

9. Wuensch C, Glueck SM, Gross J, Koszelewski D, Schober M, Faber K. Regioselective Enzymatic Carboxylation of Phenols and Hydroxystyrene Derivatives. Org Lett. 2012; 14:1974-1977. [PubMed: 22471935]

10. Plasch K, Resch V, Hitce J, Popłoński J, Faber K, Glueck SM. Regioselective Enzymatic Carboxylation of Bioactive (Poly) phenols. Adv Synth Catal. 2017; 359:959-965. [PubMed: 28450825]

11. Yoshida M, Fukuhara N, Oikawa T. Thermophilic, reversible gamma-resorcylate decarboxylase from Rhizobium sp. strain MTP-10005: purification, molecular characterization, and expression. J Bacteriol. 2004; 186:6855-6863. [PubMed: 15466039]

12. Ishii Y, Narimatsu Y, Iwasaki Y, Arai N, Kino K, Kirimura K. Reversible and nonoxidative gammaresorcylic acid decarboxylase: characterization and gene cloning of a novel enzyme catalyzing carboxylation of resorcinol, 1,3-dihydroxybenzene, from Rhizobium radiobacter. Biochem Biophys Res Commun. 2004; 324:611-620. [PubMed: 15474471]

13. Yoshida T, Hayakawa Y, Matsui T, Nagasawa T. Purification and characterization of 2,6dihydroxybenzoate decarboxylase reversibly catalyzing nonoxidative decarboxylation. Arch Microbiol. 2004; 181:391-397. [PubMed: 15118811]

14. Matsui T, Yoshida T, Yoshimura T, Nagasawa T. Regioselective carboxylation of 1,3dihydroxybenzene by 2,6-dihydroxybenzoate decarboxylase of Pandoraea sp. 12B-2. Appl Microbiol Biotechnol. 2006; 73:95-102. [PubMed: 16683134] 
15. Kasai D, Araki N, Motoi K, Yoshikawa S, Ino T, Imai S, Masai E, Fukuda M. $\gamma$-Resorcylate catabolic-pathway genes in the soil actinomycete Rhodococcus jostii RHA1. Appl Environ Microbiol. 2015; 81:7656-7665. [PubMed: 26319878]

16. Yoshida M, Oikawa T, Obata H, Abe K, Mihara H, Esaki N. Biochemical and genetic analysis of the $\gamma$-resorcylate (2,6-dihydroxybenzoate) catabolic pathway in Rhizobium sp strain MTP-10005: identification and functional analysis of its gene cluster. J Bacteriol. 2007; 189:1573-1581. [PubMed: 17158677]

17. Goto M, Hayashi H, Miyahara I, Hirotsu K, Yoshida M, Oikawa T. Crystal structures of nonoxidative zinc-dependent 2,6-dihydroxybenzoate ( $\gamma$-resorcylate) decarboxylase from Rhizobium sp. strain MTP-10005. J Biol Chem. 2006; 281:34365-34373. [PubMed: 16963440]

18. Seibert CM, Raushel FM. Structural and Catalytic Diversity within the Amidohydrolase Superfamily. Biochemistry. 2005; 44:6383-6391. [PubMed: 15850372]

19. Vladimirova A, Patskovsky Y, Fedorov AA, Fedorov EV, Bonanno JB, Toro R, Hillerich B, Seidel R, Richards NGJ, Almo SC, Raushel FM. Substrate Distortion and the Catalytic Reaction Mechanism of 5-Carboxyvanillate Decarboxylase. J Am Chem Soc. 2016; 138:826-836. [PubMed: 26714575]

20. Sauder JM, Rutter ME, Bain K, Rooney I, Gheyi T, Atwell S, Thompson DA, Emtage S, Burley SK. High Throughput Protein Production and Crystallization at NYSGXRC. Methods in Molecular Biology. 2008; 426:561-575. [PubMed: 18542890]

21. Minor W, Cymborowski M, Otwinowski Z, Chruszcz M. HKL-3000: the integration of data reduction and structure solution-from diffraction images to an initial model in minutes. Acta Crystallogr, Sect D: Biol Crystallogr. 2006; 62:859-866. [PubMed: 16855301]

22. Collaborative Computational Project Number 4 The CCP4 Suit: Programs for Protein Crystallography. Acta Crystallogr, Sect D: Biol Crystallogr. 1994; 50:760-763. [PubMed: 15299374]

23. Lamzin VS, Wilson KS. Automated refinement of protein models. Acta Crystallogr, Sect D: Biol Crystallogr. 1993; 49:129-147. [PubMed: 15299554]

24. Murshudov GN, Vagin AA, Dodson EJ. Refinement of macromolecular structures by the maximum-likelihood method. Acta Crystallogr, Sect D: Biol Crystallogr. 1997; 53:240-255. [PubMed: 15299926]

25. Emsley P, Cowtan K. Coot: model-building tools for molecular graphics. Acta Crystallogr, Sect D: Biol Crystallogr. 2004; 60:2126-2132. [PubMed: 15572765]

26. Delano, WL. The PyMOL Molecular Graphics System. Delano Scientific; San Carlos, CA: 2002.

27. Frisch, MJ., Trucks, GW., Schlegel, HB., Scuseria, GE., Robb, MA., Cheeseman, JR., Scalmani, G., Barone, V., Mennucci, B., Petersson, GA., Nakatsuji, H., Caricato, M., Li, X., Hratchian, HP., Izmaylov, AF., Bloino, J., Zheng, G., Sonnenberg, JL., Hada, M., Ehara, M., Toyota, K., Fukuda, R., Hasegawa, J., Ishida, M., Nakajima, T., Honda, Y., Kitao, O., Nakai, H., Vreven, T., Montgomery, JA., Jr, Peralta, JE., Ogliaro, F., Bearpark, M., Heyd, JJ., Brothers, E., Kudin, KN., Staroverov, VN., Keith, T., Kobayashi, R., Normand, J., Raghavachari, K., Rendell, A., Burant, JC., Iyengar, SS., Tomasi, J., Cossi, M., Rega, N., Millam, JM., Klene, M., Knox, JE., Cross, JB., Bakken, V., Adamo, C., Jaramillo, J., Gomperts, R., Stratmann, RE., Yazyev, O., Austin, AJ., Cammi, R., Pomelli, C., Ochterski, JW., Martin, RL., Morokuma, K., Zakrzewski, VG., Voth, GA., Salvador, P., Dannenberg, JJ., Dapprich, S., Daniels, AD., Farkas, O., Foresman, JB., Ortiz, JV., Cioslowski, J., Fox, DJ. Gaussian 09, revision D.01;. Gaussian, Inc; Wallingford, CT: 2013.

28. Becke AD. Density functional Thermochemistry. III. The Role of Exact Exchange. J Chem Phys. 1993; 98:5648-5652.

29. Lee C, Yang W, Parr RG. Development of the Colle-Salvetti Correlation-energy Formula into a Functional of the Electron Density. Phys Rev B. 1988; 37:785-789.

30. Grimme S, Antony J, Ehrlich S, Krieg H. A Consistent and Accurate Ab Initio Parametrization of Density Functional Dispersion Correction (DFT-D) for the 94 Elements H-Pu. J Chem Phys. 2010; 132:154104. [PubMed: 20423165]

31. Grimme S, Ehrlich S, Goerigk L. Effect of the Damping Function in Dispersion Corrected Density Functional Theory. J Comput Chem. 2011; 32:1456-1465. [PubMed: 21370243] 
32. Hay PJ, Wadt WR. Ab Initio Effective Core Potentials for Molecular Calculations. Potentials for the Transition Metal Atoms Sc to Hg. J Chem Phys. 1985; 82:270-283.

33. Marenich AV, Cramer CJ, Truhlar DG. Universal Solvation Model Based on Solute Electron Density and on A Continuum Model of the Solvent Defined by the Bulk Dielectric Constant and Atomic Surface Tensions. J Phys Chem B. 2009; 113:6378-6396. [PubMed: 19366259]

34. Lind MES, Himo F. Theoretical Study of Reaction Mechanism and Stereoselectivity of Arylmalonate Decarboxylase. ACS Catal. 2014; 4:4153-4160.

35. Sheng X, Lind MES, Himo F. Theoretical Study of the Reaction Mechanism of Phenolic Acid Decarboxylase. FEBS J. 2015; 282:4703-4713. [PubMed: 26408050]

36. Sheng X, Zhu W, Huddleston JP, Xiang DF, Raushel FM, Richards NG, Himo F. A Combined Experimental-Theoretical Study of the LigW-Catalyzed Decarboxylation of 5-Carboxyvanillate in the Metabolic Pathway for Lignin Degradation. ACS Catal. 2017; 7:4968-4974.

37. Siegbahn PEM, Himo F. Recent developments of the quantum chemical cluster approach for modeling enzyme reactions. J Biol Inorg Chem. 2009; 14:643-651. [PubMed: 19437047]

38. Blomberg MRA, Siegbahn PEM. Quantum chemical studies of proton-coupled electron transfer in metalloenzymes. Chem Rev. 2010; 110:7040-7061. [PubMed: 20677732]

39. Siegbahn PEM, Himo F. The quantum chemical cluster approach for modeling enzyme reactions. Comput Mol Sci. 2011; 1:323-336.

40. Blomberg MRA, Borowski T, Himo F, Liao RZ, Siegbahn PEM. Quantum chemical studies of mechanisms for metalloenzymes. Chem Rev. 2014; 114:3601-3658. [PubMed: 24410477]

41. Himo F. Recent Trends in Quantum Chemical Modeling of Enzymatic Reactions. J Am Chem Soc. 2017; 139:6780-6786. [PubMed: 28493715] 


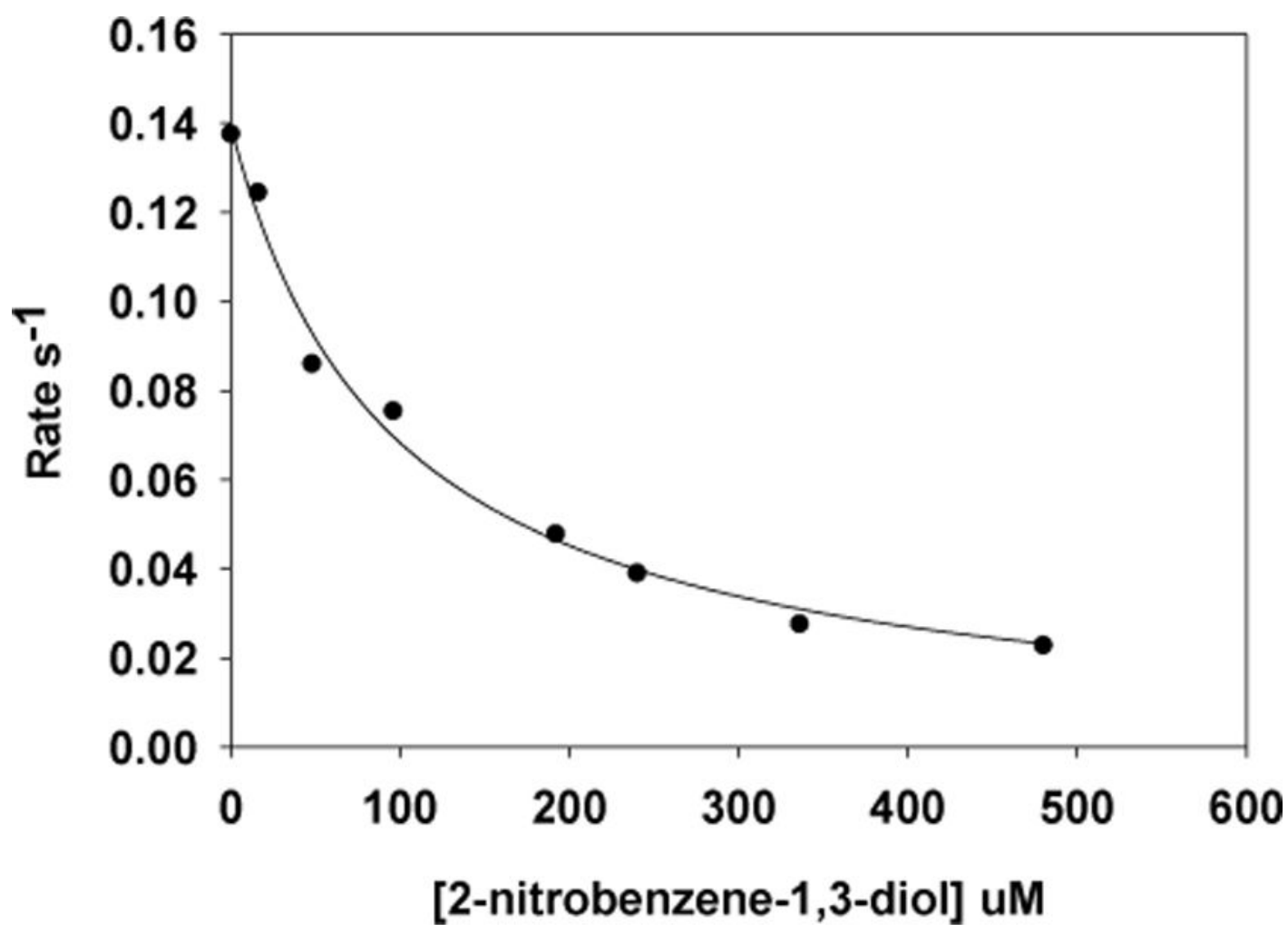

Figure 1.

Inhibition of the reaction catalyzed by $\gamma$-RSD in the presence of 2-nitroresorcinol (2-NR) with data fitted to eqn. 2 , where $\mathrm{K}_{\mathrm{i}}$ app is the apparent inhibition constant. 


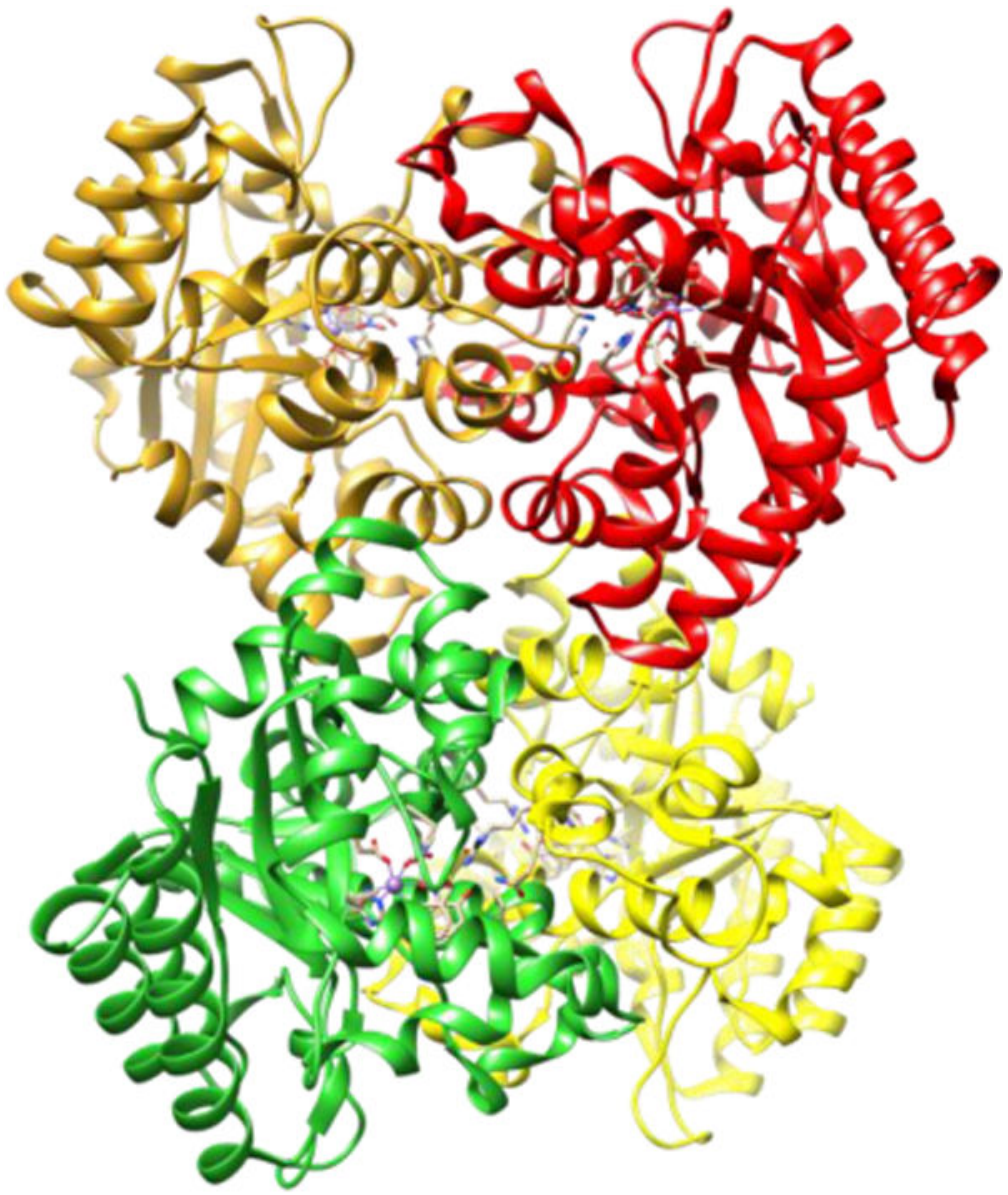

Figure 2.

Quaternary structure of $\gamma$-RSD from Polaromonas sp. JS666 (PDB entry 4QRO). The residues that coordinate the active site $\mathrm{Mn}^{2+}$ are highlighted. 

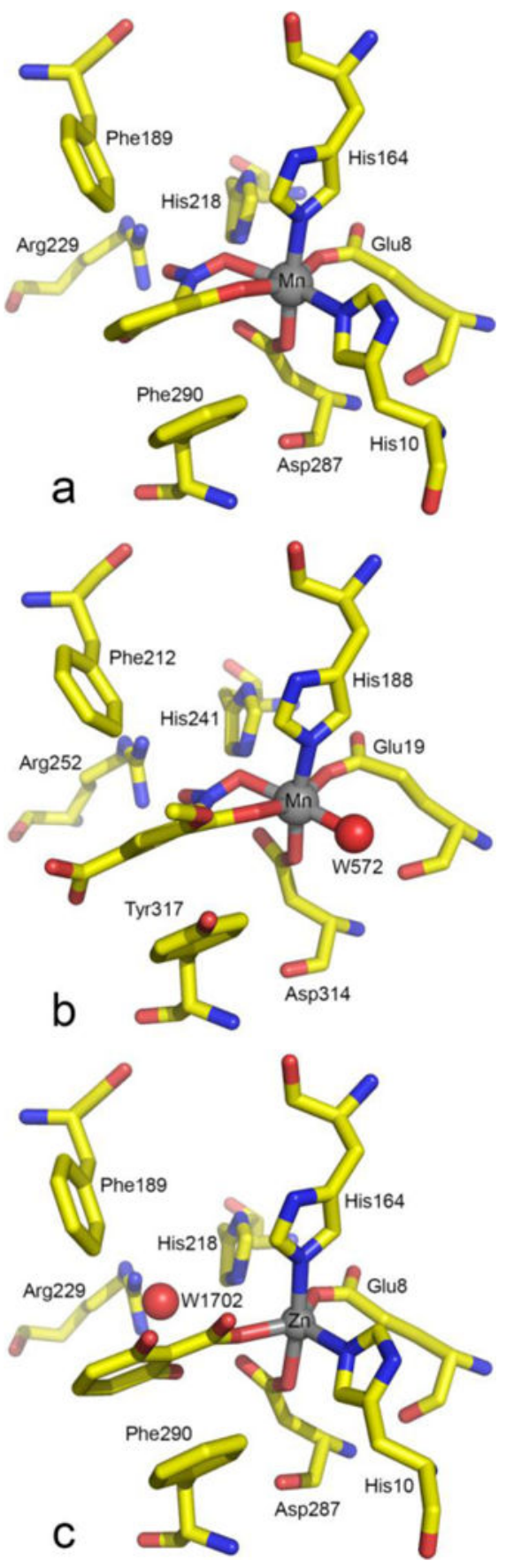

Figure 3.

Active site structures of (a) $\gamma$-RSD from Polaromonas sp. JS6666 (PDB entry 4QRO), (b) LigW from Novosphingobium aromaticivorans (PDB entry 4QRN), and (c) $\gamma$-RSD from Rhizobium sp. MTP-10005 (PDB entry 2DVU). 

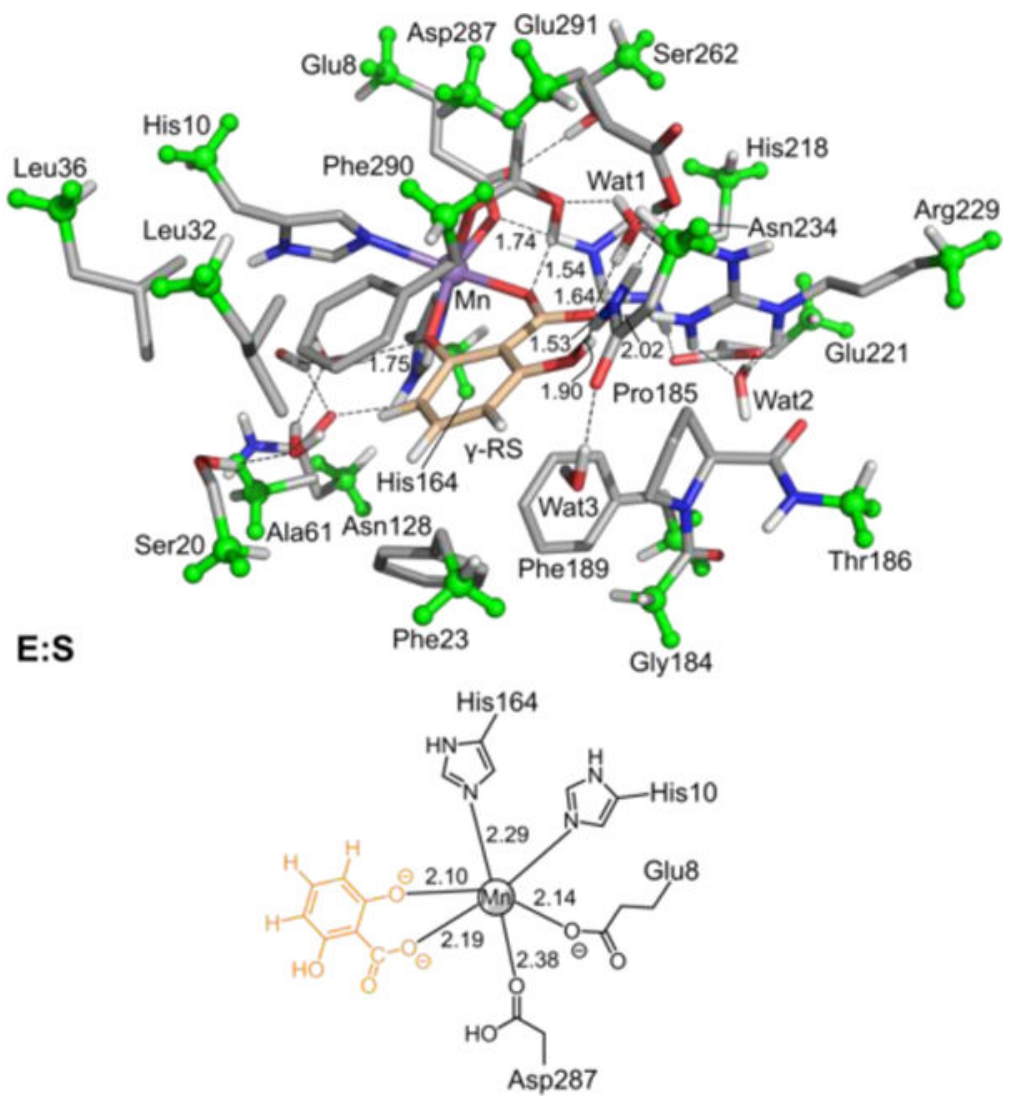

Figure 4.

Optimized structure of the active site model for $\gamma$-RSD designed on the basis of the crystal structure from Polaromonas sp. (PDB entry 4QRO). For clarity, only the polar hydrogens and hydrogens on the substrate and truncated bonds are shown. Atoms fixed during geometry optimization are shown in green. Selected distances are given in angstrom. 


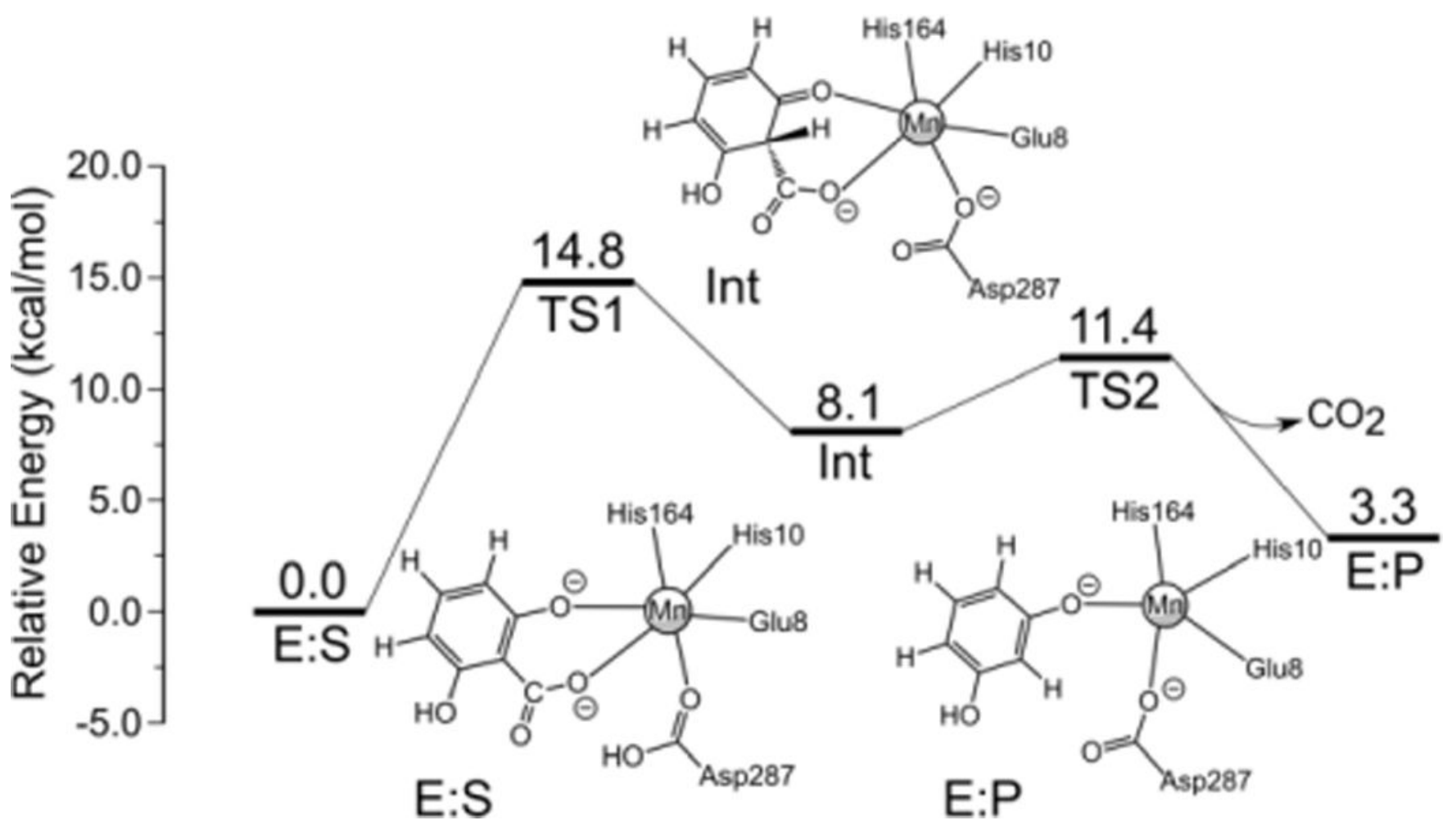

Figure 5.

Calculated energy profile for the mechanism proposed on the basis of the DFT calculations. 

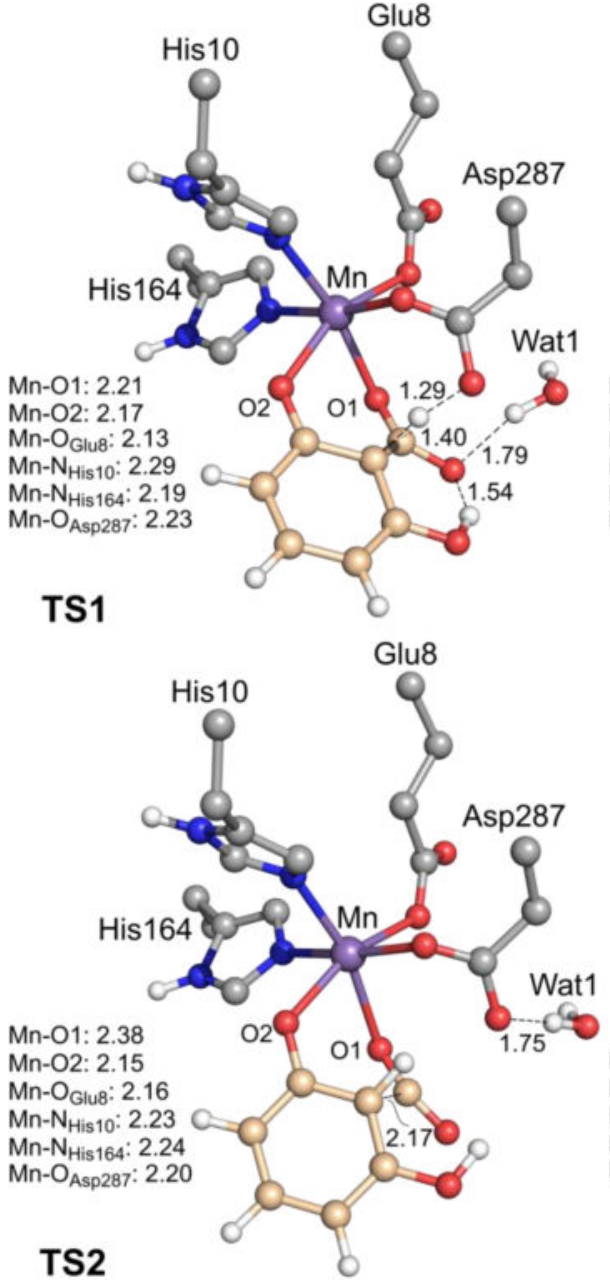

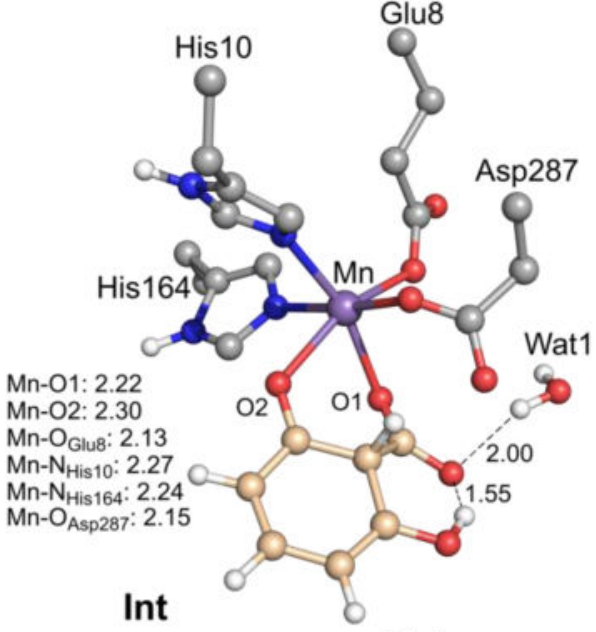

Int

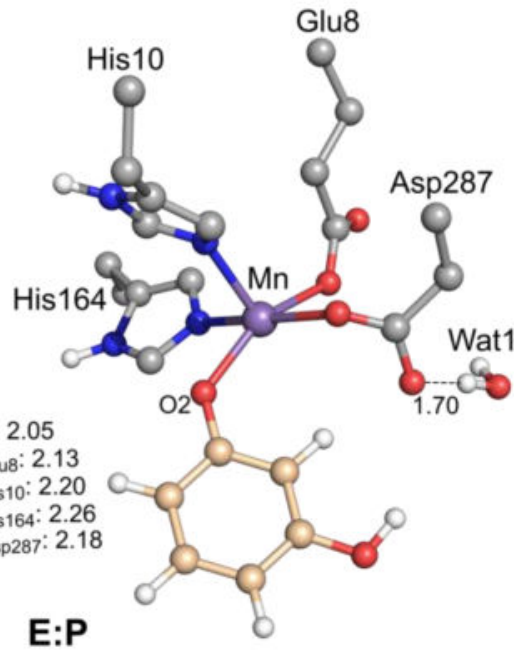

Figure 6.

Optimized structures of the stationary points along the proposed reaction pathway. For clarity, only a small part of the model is shown here. Distances are given in angstrom. 

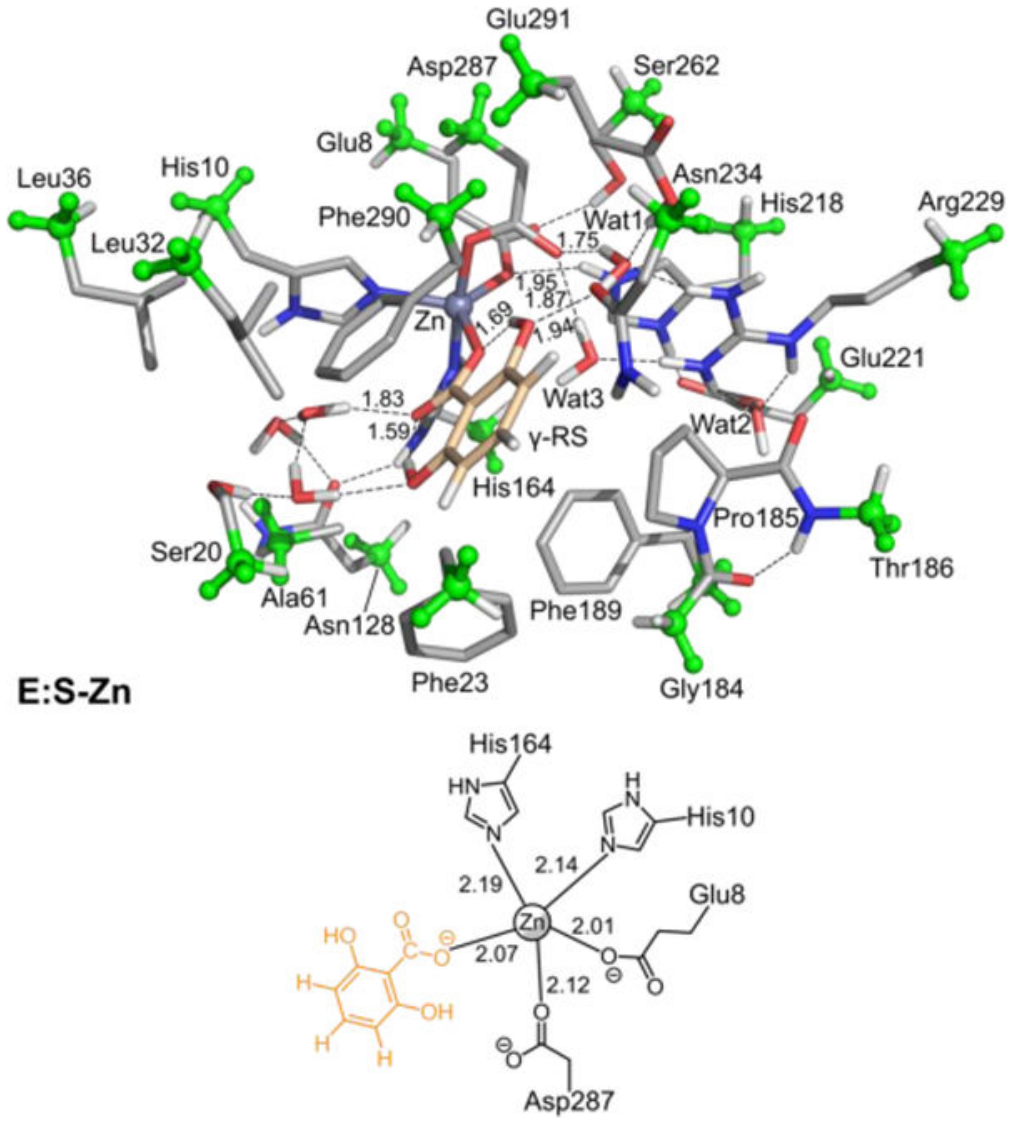

Figure 7.

Optimized structure of the active site model for $\gamma$-RSD designed on the basis of the crystal structure from Rhizobium sp. (PDB entry 2DVU) containing $\mathrm{Zn}^{2+}$ with the substrate bound in a monodentate fashion by the carboxylate group. For clarity, only polar hydrogen atoms and hydrogens on the substrate and truncated bonds are shown. Atoms fixed during geometry optimization are shown in green. 

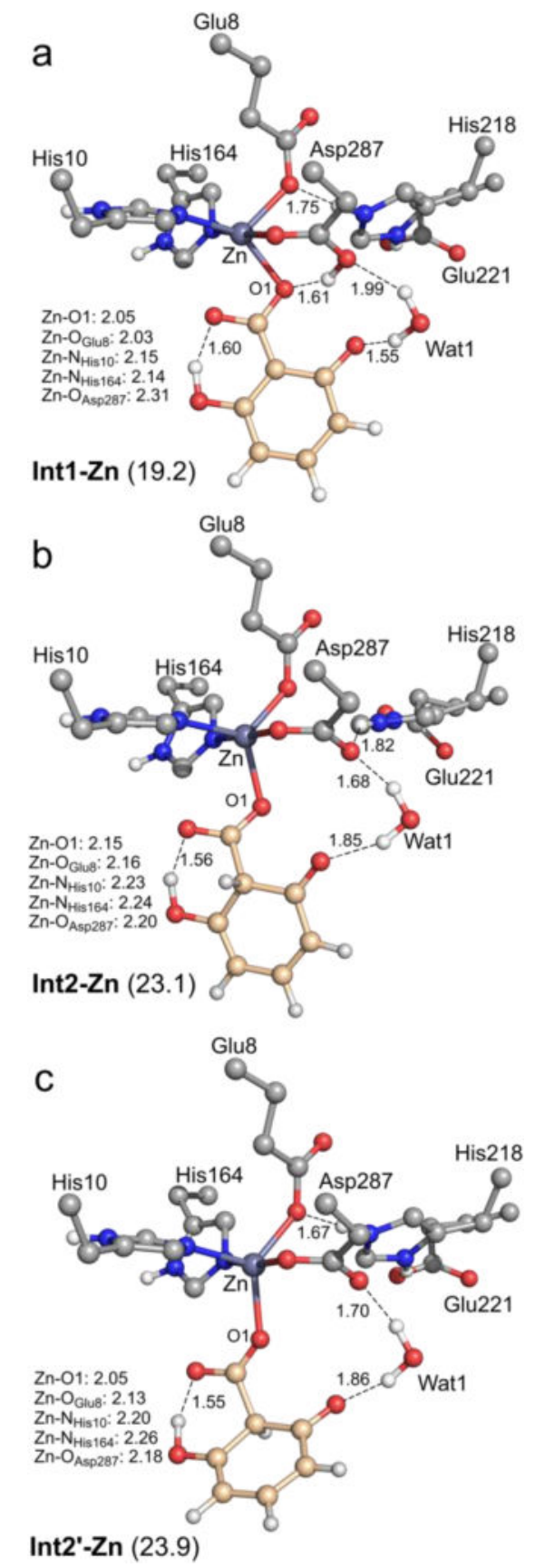

Figure 8.

Optimized structures of the intermediates along the previously proposed reaction pathway for the $\boldsymbol{\gamma}$-RSD from Rhizobium sp. shown in Scheme 2. In the case of Int2 ${ }^{\prime}-\mathbf{Z n}$ (c), the proton of Asp287 transfers to His218 spontaneously during the geometry optimization. For clarity, only a small part of the model is shown here. The calculated energies relative to E:S$\mathbf{Z n}$ are also given (in $\mathrm{kcal} / \mathrm{mol}$ ). Distances are given in angstrom. 
a<smiles>O=C(O)c1ccccc1O</smiles>

b<smiles>COc1cc(C(=O)O)cc(C(=O)O)c1O</smiles>

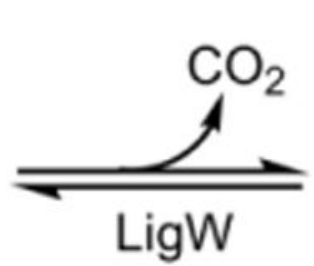

Scheme 1.

Reactions catalyzed by $\gamma$-RSD (a) and $\operatorname{LigW}(b)$.

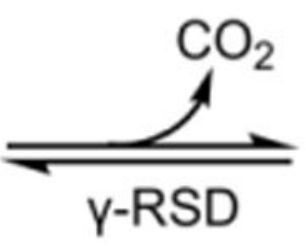<smiles>Oc1ccccc1</smiles><smiles>COc1ccc(C(=O)O)cc1O</smiles> 

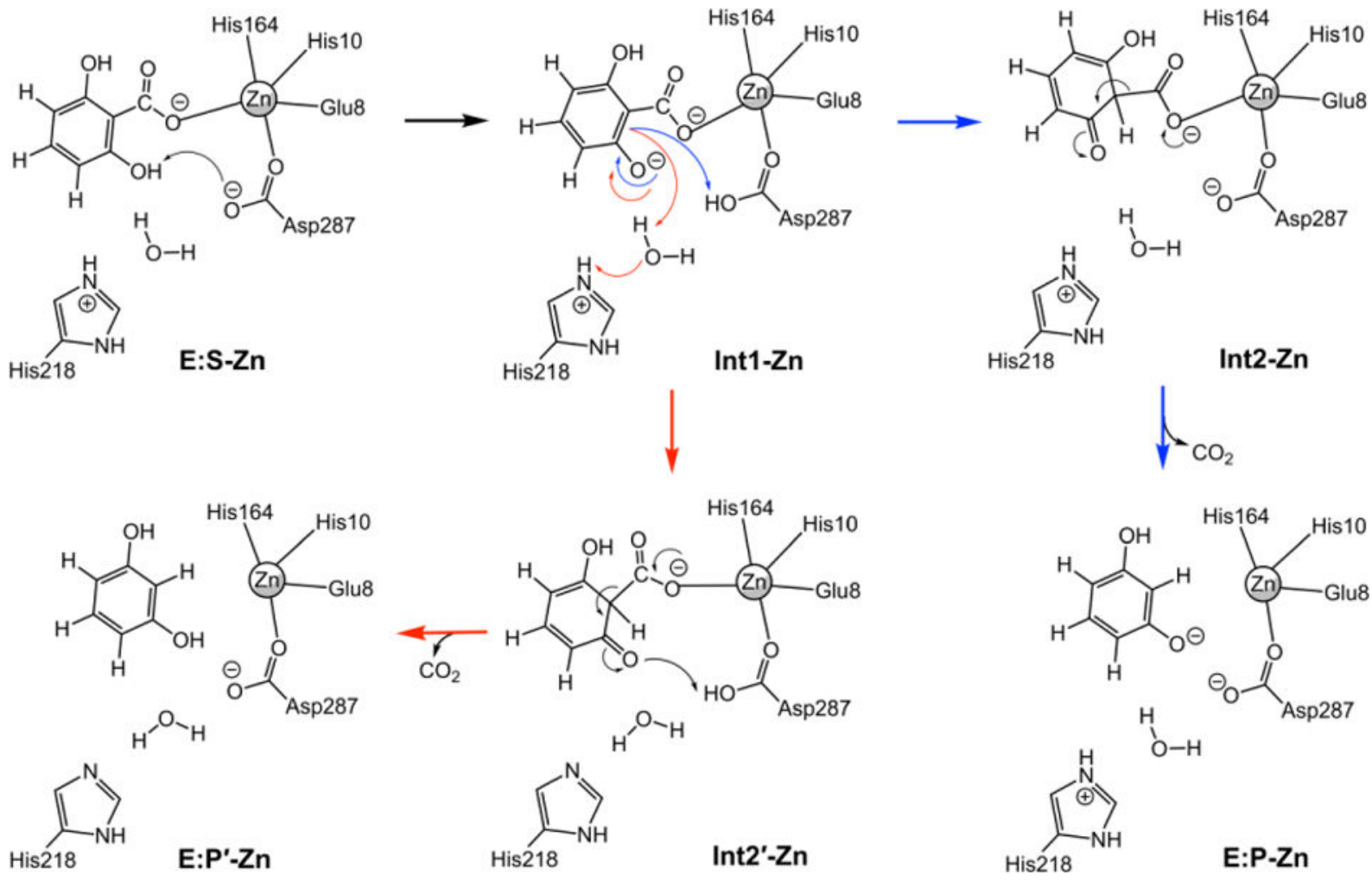

Scheme 2.

Possible reaction mechanisms proposed on the basis of the structure of the $\mathrm{Zn}$-containing $\gamma$ RSD from Rhizobium sp. 


\section{Table 1}

\section{Data Collection and Refinement Statistics}

\begin{tabular}{|c|c|}
\hline PDB identifier & 4QRO \\
\hline \multicolumn{2}{|l|}{ Data collection } \\
\hline Space group & P $12{ }_{1} 1$ \\
\hline Unit cell dimension $(\AA)$ & $\mathrm{a}=80.958, \mathrm{~b}=151.058, \mathrm{c}=143.826$ \\
\hline Unit cell angles $\left(^{\circ}\right)$ & $\beta=92.15$ \\
\hline Molecules per ASU & 8 \\
\hline Solvent content $(\%)$ & 55.0 \\
\hline Beamline & NSLS X29A \\
\hline Wavelength $(\AA)$ & 1.075 \\
\hline Structure solution method & MR \\
\hline Resolution & $50.00-1.65(1.69-1.65)$ \\
\hline Unique reflections & 412849 \\
\hline$R_{\text {merge }}$ & $0.098(0.67)$ \\
\hline Completeness (\%) & $99.8(99.8)$ \\
\hline Redundancy & $3.9(3.6)$ \\
\hline$I / \sigma(I)$ & $12.4(1.50)$ \\
\hline \multicolumn{2}{|l|}{ Refinement } \\
\hline Resolution $(\AA)$ & $50.00-1.65(1.68-1.65)$ \\
\hline$R_{\text {work }}$ & $0.189(0.363)$ \\
\hline$R_{\text {free }}$ & $0.223(0.358)$ \\
\hline \multicolumn{2}{|l|}{ Number of atoms } \\
\hline Protein & 21,059 \\
\hline Water & 180 \\
\hline Ligand & 2,241 \\
\hline Ligand identity & $\begin{array}{l}\mathrm{Mn}^{2+}, \text { 2-nitroresorcinol, glycerol, } \\
\text { bicarbonate, acetate }\end{array}$ \\
\hline \multicolumn{2}{|l|}{$<\mathrm{B}$-factor $>$} \\
\hline Protein & 34.7 \\
\hline Water & 43.2 \\
\hline Ligand & 41.8 \\
\hline \multicolumn{2}{|l|}{ RMSD } \\
\hline Bonds lengths & 0.012 \\
\hline Bond angles & 1.476 \\
\hline \multicolumn{2}{|l|}{ Ramachandran plot statistics } \\
\hline Most favored regions (\%) & 97.4 \\
\hline Allowed regions (\%) & 2.3 \\
\hline Outliers (\%) & $0.30 ;$ Trp-187 in all chains except $F$ \\
\hline
\end{tabular}

Biochemistry. Author manuscript; available in PMC 2019 June 05. 
Table 2

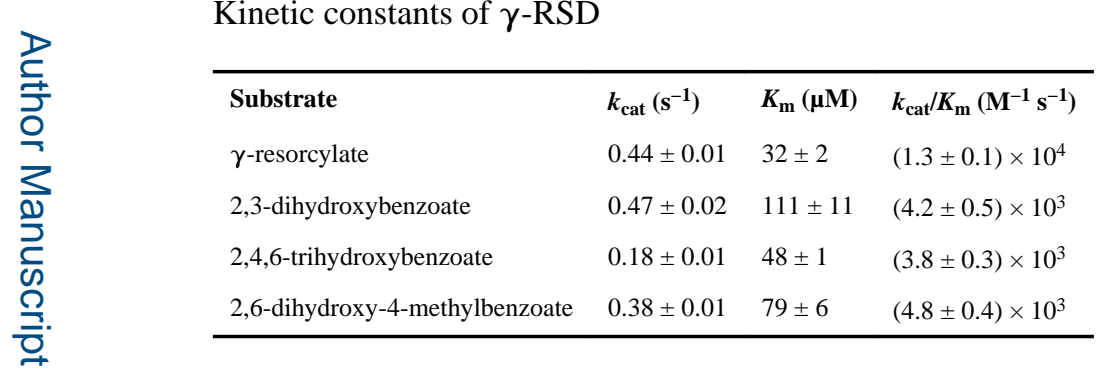

